\title{
Studies on influenza vaccine in industry
}

\author{
J. W. G. SMITH \\ M.D., M.R.C.Path., Dip. Bact. \\ R. Pollard \\ M.Sc.
Epidemiological Research Laboratory, Public Health Laboratory Service, Colindale Avenue, London N.W.9

\begin{abstract}
Summary
Large scale studies of influenza vaccination in industry have recently been started. The studies are of two types:
\end{abstract}

(a) Vaccination was offered to a factory and a record maintained of sickness absence of all employees, both the vaccinated volunteers and the nonvolunteers. In five different factories, the average acceptance rate was $42 \%$.

An analysis of the volunteers in one factory indicated that acceptance of vaccination was highest in middle-aged married women and low in younger and older men.

(b) In the Post Office telecommunications branch vaccination was offered to 26,317 employees in eightyeight units in different parts of the country; $42 \%$ of these accepted vaccination. Ninety-eight other units, employing 25,202 employees, are acting as unvaccinated controls. Sickness absence is being recorded in both groups of units.

In both these groups of studies it is aimed to compare the absence experience of the immunized and non-immunized groups for a prolonged period, both when influenza is and is not occurring.

Preliminary findings are presented of the absence figures for January and February 1972, during which time a mild outbreak of influenza occurred, with only a small effect on sickness absence. Vaccinated persons in factories had lower absence rates than the nonvaccinated persons, and telecommunications units in which vaccination was offered experienced lower absence rates with less respiratory absence.

The significance of these findings is discussed.

\section{Introduction}

Although influenza vaccine has been available for many years, and despite numbers of studies made in industry (e.g. MRC Report, 1964; Edmondson et al., 1971; Seratai, 1971), there is still considerable doubt as to whether annual vaccination in industry would reduce sickness sufficiently to warrant the expense of industrial immunization schemes. On the one hand, apart from its effect on the individual and the family, sickness during influenza outbreaks may result in serious industrial disruption. On the other hand, there are doubts about the degree and duration of the protection conferred by the vaccine, and in years in which an outbreak does not occur, even a highly effective vaccine could clearly not materially affect the level of sickness absence. Furthermore, too few employees might accept vaccination for there to be any noticeable effect on absence in a succeeding outbreak.

Assessments of influenza vaccine in industry are difficult to make. The trials must be large because the size of an influenza outbreak cannot be forecast and the attack-rate might be low. It is difficult to persuade large numbers of industrial workers to take part in a fully controlled study with vaccinated and placebo-inoculated groups chosen by random allocation. Industrial concerns, and unions, will often agree only when vaccine is offered to all employees. Thus, the comparison lies between those who volunteer and those who do not and is open to the objection that those who volunteer may well be dissimilar from those who do not. Such dissimilarities may be associated with differences in their liability to influenza and to sickness absence in general.

However, it is undoubtedly important to determine how influenza vaccine should be used in industry, and the PHLS, in co-operation with industrial organizations and with the Post Office, has begun studies which try to overcome these difficulties and will provide a real measure of the value of influenza vaccine in preventing sickness absence in industry.

The studies are of two types:

(1) Those made in individual factories in which an offer of vaccination is made to the employees. A comparison is then made of sickness absence among vaccinated and unvaccinated employees.

(2) An investigation made in the telecommunications branch of the Post Office. In this study vaccination is offered to all employees in a large number of telephone exchanges and administrative units. These exchanges and units are matched according to location and number of persons employed with 
similar units in which vaccine was not offered. The comparison in this study is of sickness absence in vaccinated and unvaccinated units.

Sickness absence in vaccinated and unvaccinated groups of individuals or in groups of industrial units may clearly differ irrespective of an effect of the vaccine. In both types of study it is proposed to assess the effect of the vaccination not solely by a direct comparison of sickness absence in vaccinated and unvaccinated groups during epidemics, but also by the trend of sickness absence observed in the two groups when influenza is epidemic and when it is not. Consequently, in both types of study the recording of absence will be made for as long a period as possible-both during outbreaks and in noninfluenza periods. The studies began in November and December, 1971, and it is planned to continue them over a number of influenza seasons. Only a few preliminary results are at present available.

\section{Procedures}

\section{(a) Studies in individual factories}

Influenza vaccination was offered to employees in five factories and arrangements were made to record for each employee, both immunized and unimmunized, all sickness absence and its cause. A single dose of vaccine was given to the volunteers using either a needle and syringe or a Portojet immunization gun. The recording of sickness absence was made by means of individual records.

\section{(b) Study comparing groups of industrial units}

In collaboration with the telecommunications branch of the Post Office, vaccination was offered to eighty-eight offices and telephone exchanges in different parts of the U.K. These units were matched for location, type of unit and number of employees with ninety-eight similar units in which vaccination was not offered. Arrangements were made to record weekly, (a) total sickness absence in each unit, and (b) the nature of the sickness in employees absent for more than 3 days who provided a medical certificate.

\section{The vaccine}

An inactivated commercial vaccine was used-. BDH Admune containing 400 CCA units of influenza $A / H K / 31 / 68$ (H3N2), and 200 units of influenza $\mathrm{B} / \mathrm{Vic} / 98926 / 70$. It was given in a single subcutaneous dose of $1 \mathrm{ml}$.
To measure the distribution of influenza antibodies in the working population serum samples were collected from student volunteers and from factory and local authority employees. The antibody content was titrated by haemagglutination-inhibition using the $\mathrm{A} / \mathrm{Hong} \mathrm{Kong} / 1 / 68$ strain of influenza virus. The titrations were made in the Public Health Laboratories at Bedford (Dr W. F. Lane), Leicester (Dr Hélène Mair) and Winchester (Dr M. H. Hughes), and also in the Wellcome Research Laboratories.

\section{Influenza in 1971-72}

An outbreak of influenza occurred in the U.K. in the winter of 1971-72. The population probably had appreciable immunity to the current influenza $\mathbf{A}$ virus at the beginning of the winter, for approximately $50 \%$ of the 466 persons tested had antibody detectable at a serum dilution of 1 in 20 or greater (Table 1).

Certain characteristics of the influenza outbreak in England and Wales are shown in Fig. 1, viz. the consultation rate for influenza reported by a number of general practitioners to the Epidemiology Unit of the Royal College of General Practitioners; the number of deaths attributed to influenza reported to the Registrar General; the weekly number of new sickness benefit claims; and the number of influenza A virus isolations reported to the Epidemiological Research Laboratory by PHLS and hospital laboratories. Many of the strains were typed in the Virus Reference Laboratory, Colindale, and most of them were A/Hong Kong/1/68 strains.

Figure 1 shows that the outbreak started in midDecember 1971, and finished at about the end of February 1972. Although a substantial number of cases was reported by family doctors, not many deaths occurred and the effect on sickness absence was small. The epidemic was not therefore a severe one, and in terms of its effect on sickness absence it must be regarded as a minor outbreak.

\section{Studies in individual factories}

In the five factories the overall acceptance rate of vaccination was $42 \%$. A preliminary analysis has been made of the acceptance rate by age and sex in one of them. This was a pharmaceutical factory with 5928 employees-the company does not manufacture vaccines. Vaccination was carried out over 3 days in December 1971 after a letter of introduction had

TABLE 1. Distribution of HI antibody to influenza $A$ in October/November 1971, in adults aged between 18 and 65 years and living in four areas in England

\begin{tabular}{rrrrrrrrrrr}
\hline & \multicolumn{1}{c}{ No. of sera with antibody at reciprocal titre of: } & \multicolumn{2}{c}{$\begin{array}{c}\text { Total no. } \\
\text { of sera }\end{array}$} \\
\hline$<10$ & 10 & 20 & 40 & 80 & 160 & 320 & 680 & 1280 & 2560 & 4 \\
\hline 152 & 83 & 71 & 58 & 37 & 34 & 22 & 7 & 1 & 1 & 466 \\
\hline
\end{tabular}




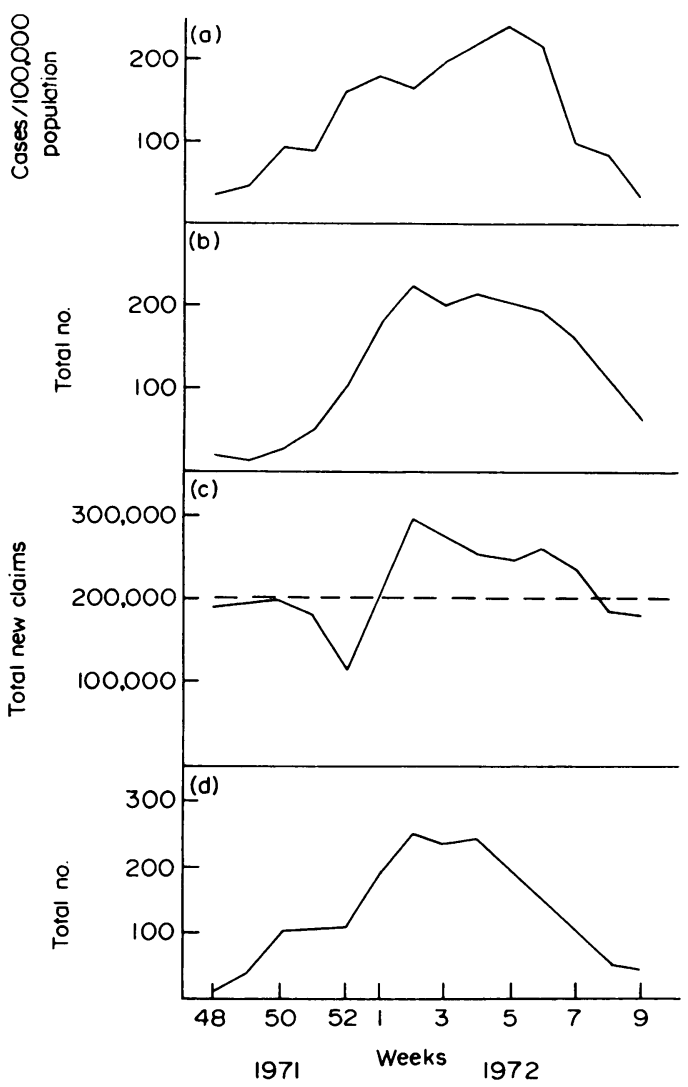

FIG. 1. Epidemiological features of influenza in England and Wales 1971-72. (a) Influenza returns from general practice, (b) influenza deaths, (c) sickness benefit claims, (d) laboratory isolates of influenza $A$. The interrupted line in (c) is the number of claims that might be expected in the absence of an influenza outbreak.

been sent to each employee and $41.7 \%$ of them accepted vaccination.

Figure 2 shows the proportion who accepted vaccination in terms of age, sex and marital status. The number of men in the different age-groups on which the points in Fig. 2 are based varied between 141 and 827 , and the number of married women between 177 and 548. The number of single women was 452 at ages $15-19,185$ at $20-24,82$ at $25-34$, 60 at $35-44,90$ at $45-54$ and 65 at 55-59. It can be seen that the highest response was among the middleaged married women $(52 \%)$, and there was also a fairly good response among the men between 25 and 34 years. The response among young men aged 15-19 years was only $31 \%$ and it was also poor in the elderly men $(34 \%)$.

\section{Sickness absence in vaccinated factories}

Table 2 shows the total number of days lost $/ 100$ employees in January and February 1972 among the vaccinated volunteers and non-volunteers in four different factories. The factories are situated in different places in England and Wales, and influenza virus was known to be causing illness in each of the areas in the period concerned. It may be seen that in each factory the number of days lost by the vaccinated employees was less than by the non-vaccinated employees.

Figure 3 shows the weekly absence rate among the vaccinated and unvaccinated weekly-paid employees in the fifth factory-the large pharmaceutical factory. Of the 3610 weekly-paid workers, mostly employed on production, $42 \%$ were vaccinated. Before the influenza outbreak began the absence rates of the vaccinated and non-vaccinated were close, but during the outbreak absence became relatively greater among the non-vaccinated. The high absence figure of both groups in the week ending 27 February is attributed by the factory medical officers to the effects of the power strike.

A more detailed analysis of the results in this

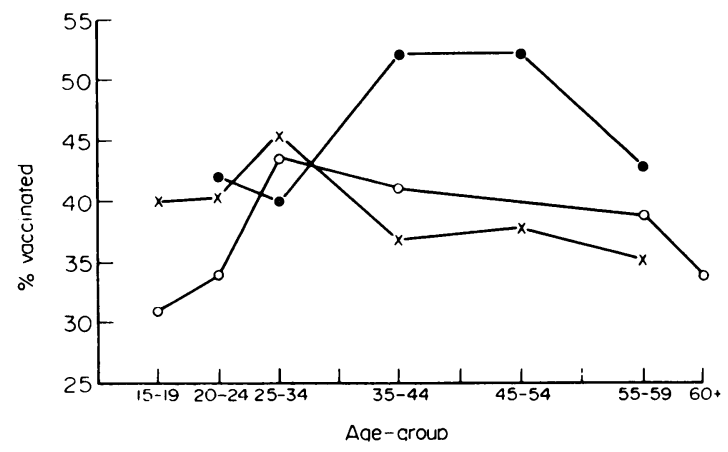

FIG. 2. The proportion of employees by age, sex and marital status, accepting influenza vaccination in a pharmaceutical factory of nearly 6000 employees. - - , Married females; $0-0$, males; $\times-\times$, single females.

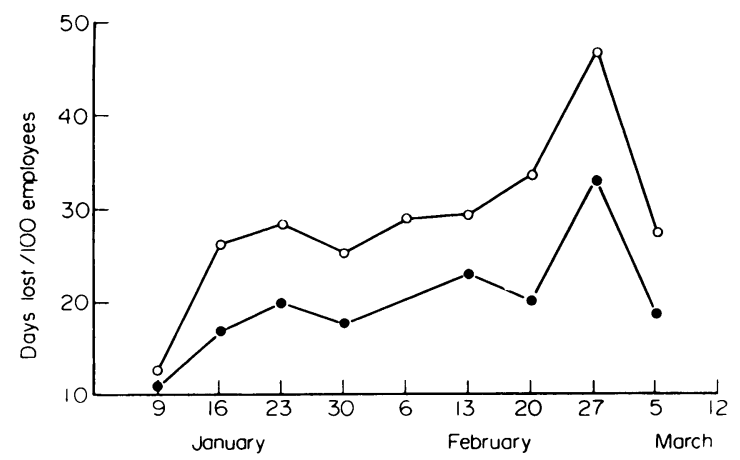

Fig. 3. The total number of working days lost in the pharmaceutical factory each week/100 weekly-paid employees. - Vaccinated; $\mathrm{O}-\mathrm{O}$, unvaccinated. 
TABle 2. Days lost/100 employees in January and February 1972 in vaccinated and non-vaccinated employees in four factories

\begin{tabular}{|c|c|c|c|c|c|}
\hline \multirow{2}{*}{ Factory } & \multirow{2}{*}{$\begin{array}{l}\text { No. in } \\
\text { factory }\end{array}$} & \multirow{2}{*}{$\begin{array}{l}\text { No. } \\
\text { vaccinated }\end{array}$} & \multicolumn{2}{|c|}{$\begin{array}{l}\text { Days lost } / 100 \text { employees } \\
\text { Total for Jan. and Feb. }\end{array}$} & \multirow{2}{*}{$\begin{array}{c}\text { Ratio } \\
\text { vacc./non-vacc. }\end{array}$} \\
\hline & & & Vaccinated & Non-vaccinated & \\
\hline A & 1215 & 540 & 36 & 55 & 0.65 \\
\hline B & 3302 & 1440 & 41 & 44 & 0.93 \\
\hline $\mathrm{C}$ & 970 & 450 & 25 & 40 & 0.63 \\
\hline D & 855 & 475 & 46 & 54 & 0.85 \\
\hline
\end{tabular}

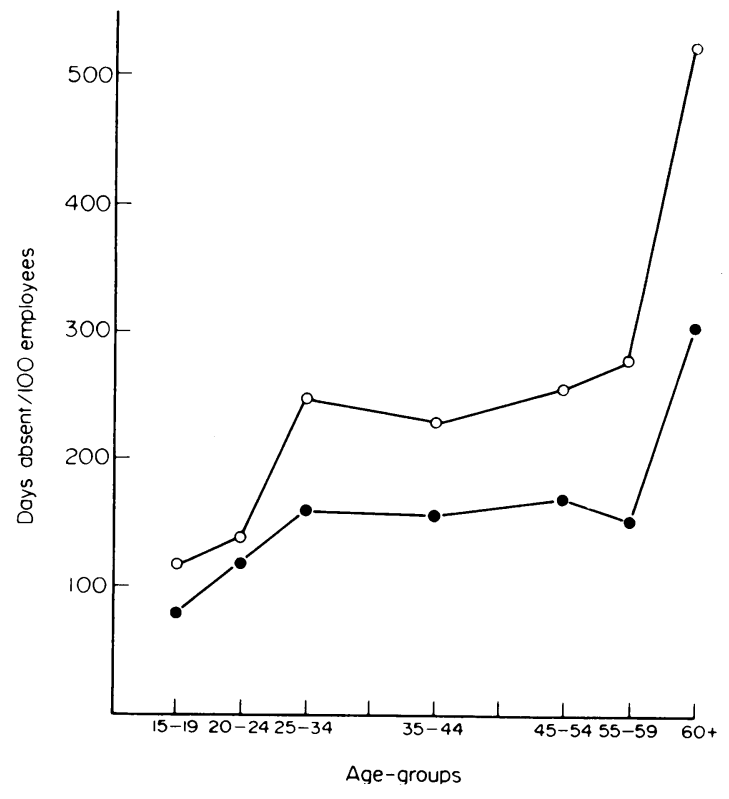

FIG. 4. The total number of days absent during January and February 1972 in vaccinated (-) and unvaccinated $(\mathrm{O}-\mathrm{O})$ male, weekly-paid employees of different age groups in the pharmaceutical factory.

pharmaceutical factory shows that the higher sickness absence among the non-volunteers was consistently observed in men, in married and unmarried women, and in both monthly-paid (office and management) and weekly-paid (production) employees. The difference was also present in all agegroups. As an example, Fig. 4 shows the absence by age-group in the male works employees. It may be seen that a particularly high rate was evident during the outbreak among older men, in whom the response to the offer of vaccination had been poor (see Fig. 2).

\section{Post Office study}

Comparison of absence in groups of vaccinated and unvaccinated units

In this study vaccination was made available to 26,317 employees in eighty-eight telecommunications units in different parts of the country. In ninety-eight units, matched with the vaccinated units for location and number of employees, vaccination was not offered and in these units 25,202 people were employed. In total, the number of employees vaccinated was $11,064-$ or $42 \%$ of those to whom the offer was made (the same figure as in the five factories). Each unit, both vaccinated and control, prepared a weekly return of the number of new absences and total days lost from sickness, together with an analysis of the medical certificates relating to sickness of more than 3 days' duration.

The returns started at the end of the first week in January 1972 and a preliminary analysis of the returns for the first 8 weeks has been made. Table 3 shows the number of days lost/100 employees in theo vaccinated and control units. A difference in favour of the vaccinated units is apparent, becoming smallek in week 6 (week ending 11 February). When the medical certificates received for respiratory illnesses are considered the difference becomes more marked (Table 4) and although the amount of respiratory illness was small, in weeks 3, 4 and 5, the number of certificates for respiratory illness was $50 \%$ greater in the non-vaccinated units. On the other hand, the number of non-respiratory medical certificates showed a greater fluctuation and the overall ratio between the vaccinated and control units was 0.98 for the 8 weeks of January and February (Table 5).

\section{Discussion}

It will not be possible to attempt to draw conclusions from the present studies (neither in those involving groups of vaccinated and non-vaccinated individuals nor those in which whole industrial units are being compared) until more adequate data have been collected concerning absence both during influenza outbreaks and during periods of appreciable duration when no influenza occurs. Nevertheless, the early observations are, perhaps, of some interest.

In the first winter of the present studies serological evidence suggested that about $50 \%$ of the working population possessed a significant level of immunity to the current strain of influenza A virus. The outbreak of influenza that occurred was mild and its 
TABLE 3. Post Office returns from week ending 8 January 1972. Days lost/100 employees

\begin{tabular}{lcccccccccc}
\hline \multicolumn{1}{c}{ Week no. } & 1 & 2 & 3 & 4 & 5 & 6 & 7 & 8 & Total average/week \\
\hline Not vaccinated & 26.6 & 26.9 & $28 \cdot 4$ & $27 \cdot 3$ & $27 \cdot 8$ & 26.9 & $24 \cdot 6$ & $23 \cdot 4$ & $211 \cdot 9$ & $26 \cdot 5$ \\
Vaccinated & $24 \cdot 1$ & $24 \cdot 5$ & $24 \cdot 3$ & $24 \cdot 2$ & $26 \cdot 1$ & $26 \cdot 5$ & $25 \cdot 5$ & $25 \cdot 7$ & $200 \cdot 9$ & $25 \cdot 1$ \\
Ratio vacc./not vacc. & 0.91 & 0.91 & 0.86 & 0.87 & 0.94 & 0.99 & 1.04 & $1 \cdot 10$ & 0.95 & 0.95 \\
\hline
\end{tabular}

TABLE 4. Number of respiratory certificates/100 employees in telecommunications units. Week 1 is week ending 8 January 1972

\begin{tabular}{|c|c|c|c|c|c|c|c|c|c|}
\hline & \multicolumn{8}{|c|}{ Week no. } & \multirow[b]{2}{*}{ Total } \\
\hline & 1 & 2 & 3 & 4 & 5 & 6 & 7 & 8 & \\
\hline Vaccinated & $0 \cdot 87$ & $1 \cdot 10$ & $1 \cdot 01$ & $1 \cdot 00$ & $1 \cdot 00$ & $1 \cdot 13$ & $1 \cdot 30$ & $1 \cdot 09$ & $8 \cdot 50$ \\
\hline Not vaccinated & $1 \cdot 15$ & $1 \cdot 25$ & $1 \cdot 52$ & $1 \cdot 51$ & $1 \cdot 48$ & $1 \cdot 30$ & $1 \cdot 13$ & $1 \cdot 14$ & $10 \cdot 48$ \\
\hline Ratio vacc./not vacc. & $0 \cdot 76$ & $0 \cdot 88$ & 0.66 & 0.66 & $0 \cdot 68$ & $0 \cdot 87$ & $1 \cdot 15$ & $0 \cdot 96$ & $0 \cdot 81$ \\
\hline
\end{tabular}

TABLE 5. Number of non-respiratory certificates/100 employees in telecommunications units. Week 1 is week. ending 8 January 1972

\begin{tabular}{|c|c|c|c|c|c|c|c|c|c|}
\hline & \multicolumn{8}{|c|}{ Week no. } & \multirow[b]{2}{*}{ Tota } \\
\hline & 1 & 2 & 3 & 4 & 5 & 6 & 7 & 8 & \\
\hline $\begin{array}{l}\text { Vaccinated } \\
\text { Not yaccinated }\end{array}$ & $\begin{array}{l}0.60 \\
0.71\end{array}$ & $\begin{array}{l}0.75 \\
0.70\end{array}$ & $\begin{array}{l}0.76 \\
0.83\end{array}$ & $\begin{array}{l}0.67 \\
1.10\end{array}$ & $\begin{array}{l}0.96 \\
0.82\end{array}$ & $\begin{array}{l}0.90 \\
0.81\end{array}$ & $\begin{array}{l}0.90 \\
0.82\end{array}$ & $\begin{array}{l}0.86 \\
0.72\end{array}$ & $\begin{array}{l}6 \cdot 40 \\
6 \cdot 51\end{array}$ \\
\hline Ratio vacc./not vacc. & 0.85 & 1.07 & 0.92 & 0.61 & $1 \cdot 17$ & $1 \cdot 11$ & $1 \cdot 10$ & $1 \cdot 19$ & 0.98 \\
\hline
\end{tabular}

effect on sickness absence small. Consequently, vaccination in industry last winter could not have been expected to have had a marked effect on sickness absence. Moreover, an effect on absence must also depend on the proportion of the factory population accepting the offer of vaccine. In these industrial studies, vaccination was offered to about 37,000 people in all and the overall acceptance was only $42 \%$, despite the use of posters, letters, and addresses to the staff, supported coincidentally by appreciable coverage in the national press discussing vaccination favourably. Consequently, the impact of vaccination in industry may be reduced appreciably by the high proportion of employees who do not come forward for vaccination.

A further matter affecting the value of vaccination concerns the nature of the volunteers who come forward. In the pharmaceutical factory the proportion accepting vaccination was greatest among the middle-aged married women-a factory with a high proportion of such employees might benefit from a vaccination campaign more than a factory employing many men in the younger or older age-groups.

In the studies in which absence is compared in individuals who volunteered to accept vaccination and those who did not, absence was found to be lower among the vaccinated. However, towards the end of the outbreak, in the last 2 weeks of February 1972, when absence rates were falling, absence among the immunized employees remained lower than among the unimmunized. There is evidence that absence due to influenza may persist after the outbreak-probably due to complications and aftereffects of the disease (Miller, Pereira \& Clark, 1971), but this winter's influenza was mild and it seems unlikely that this factor alone accounts for the persisting difference. Any assessment of the role of vaccination will depend on the extent to which the two rates come together in the weeks and months after the outbreak-if they come together at all.

When the absence record during the outbreak of the different age-groups was examined (Fig. 4), absence was particularly marked in older employees, among whom the proportion accepting vaccination was low (Fig. 2). There may therefore exist groups of employees, reluctant to accept vaccination, with a poor sickness absence-record and who might also be particularly liable to be off sick during an outbreak.

A difference in sickness absence in the vaccinated and non-vaccinated groups during an influenza outbreak could therefore be due to:

(1) the prevention of influenza by vaccination;

(2) the placebo effect-i.e. that the act of volunteering and accepting an injection may influence sickness absence. Thus, volunteers who develop influenza may be inclined to dismiss it lightly, provided it is not too severe. Moreover, only a proportion of absence during an outbreak is due to influenza; some must be caused by colds and other respiratory disease and some might well be due to the grasping of a ready excuse to be away ill;

(3) that those who volunteer are the sort of people 
who are less liable to be ill than the remainder of the factory population, perhaps because they are fitter or take more care of themselves, or because they are less inclined to notice mild illness.

By continuing the analysis of absence much information on the records of volunteers and nonvolunteers should be obtained, so that an estimate of the importance of the third factor should be possible. The importance of the second factor, i.e. the placebo effect, can only be determined by a controlled trial using a placebo vaccine, and such studies are in progress.

The Post Office investigation, however, is planned to give valid data of the value of offering vaccination to an industrial unit. By taking sufficient units scattered over the country and comparing the experience of vaccinated and non-vaccinated units, the value of offering vaccination should be measurable. Thus, the number of potential volunteers must be very similar in the control units which were not offered vaccination. The preliminary findings indicate that the 'vaccinated' units did have lower sickness absence figures than the unvaccinated units. A measure of the effect of vaccination will again depend on the findings during the period when no influenza is occurring. If the absence rates in the two groups of units remain apart, it will suggest that vaccination had no real effect. If, on the other hand, the rates come together, it should be possible to suggest that the difference observed during the outbreak is due to vaccination. Whilst it might be argued that an offer of an inert vaccine could have accounted for any effect observed, it is nevertheless true that good evidence exists that influenza vaccine is protective (Eickhoff, 1971) and, moreover, the effect of vaccine in an industrial concern will inevitably include any placebo effect and in estimating the value of vaccination to the management of an industrial concern it is necessary to consider the overall effect of the vaccination campaign.

\section{Acknowledgments}

We wish to thank Sir Austin Bradford Hill, F.R.s., for his help in planning the studies and in analysing the findings. We should also like to thank the many other colleagues, medical, administrative and secretarial who have played important parts in organization and immunization, recording and analysis.

\section{References}

Edmondson, W.P., Rottenburg, R., White, P.W. \& GWALTNEY, J.M. (1971) A comparison of subcutaneous, nasal and combined influenza vaccination. II. Protection against natural challenge. American Journal of Epidemio$\log y, 93,480$.

EICKHOFF, T.C. (1971) Immunization against influenza: rationale and recommendations. Committee on immunization of the Infectious Diseases Society of America. The Journal of Infectious Diseases, 123, 446.

Miller, D.L., Pereira, M.S. \& Clarke, M.(1971) Epidemiology of the Hong Kong/68 variant of influenza A2 in Britain. British Medical Journal, 1, 475.

MRC REPORT (1964) Clinical trials of oil-adjuvant influenzao vaccines, 1960-3. Report of the Medical Research Councis by its committee on influenza and other respiratory viruse vaccines. British Medical Journal, 2, 267.

SerataI, A. (1971) Influenza inoculations for the staff of the SBB and Swiss postal services, August 1970. Schweizerische Medizinische Wochenschrift, 101, 1693. 